\title{
Polycyclic aromatic hydrocarbons (PAHs) in sediments from Prai and Malacca Rivers, Peninsular Malaysia
}

\begin{abstract}
In this study the surface sediments of Malacca River (3 Stations) and Prai River (3 Stations) were analyzed to identify the distributions of PAHs. The concentrations of PAHs were quantified using Gas Chromatographyï Mass Spectrometer (GCïMS). Total PAH concentrations varied from 716 to 1210 and 1102 to $7938 \mathrm{ng}$ gi $1 \mathrm{dw}$ in sediments of Malacca and Prai Rivers, respectively. The concentrations of PAHs in sediments were classified as moderate in sediments of Malacca and high to very high level of pollution in sediments of Prai River. PAHs were dominated by high molecular weight (HMW) in sediments of Malacca River and low molecular weight (LMW) in sediments of Prai River. This indicates that petroleum hydrocarbon pollution in Malacca River is dominated by atmospheric input while that of Prai River is mostly fresh petrogenic input from lateral or horizontal transport via rivers and surface runoffs. The other diagnostic ratios of LMW/HMW, Fluo/(Fluo + Py), Fluo/Py and Comb/TPH in both rivers are consistent with the above statement.
\end{abstract}

Keyword: Polycyclic aromatic hydrocarbons (PAHs); Petrogenic; Pyrogenic; Sediment; Prai River; Malacca River; Malaysia 